\title{
Aproximaciones a la onomástica indígena del Austro lojano
}

Jorge Gómez Rendón*

\begin{abstract}
RESUMEN
El Austro lojano fue siempre una zona de contacto entre varios ecosistemas y formaciones

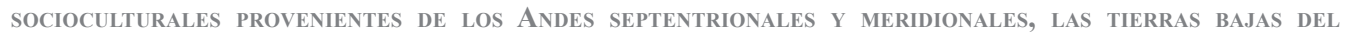
Pacífico y la Amazonía. El presente estudio explora la composición lingǘística del Austro lojano a través del estudio de la onomástica de una zona en particular, la de Chuquiribamba. Los resultados PRELIMINARES DE LA SEGMENTACIÓN MORFOLÓGICA DE LOS PATRONíMICOS NO-ESPAÑOLES DEMUESTRAN dOS VERTIENTES ETNOLINGÜÍSTICAS, LA KICHWA Y LA NO-KICHWA, INCLUYENDO EN ESTA ÚLTIMA FORMAS QUE SUGIEREN CONEXIONES NO SÓLO CON LAS EXTINTAS LENGUAS PURUHÁ Y CAÑARI, SINO TAMBIÉN CON VARIEDADES DE LA FAMILIA Chicham habladas EN El Piedemonte ORIENTAL de los ANDES.
\end{abstract}

Palabras claves: onomástica - patronímicos - lenguas prequechuas - Puruhá - cañari.

\section{Abstract}

The Austro lojano was always an area of contact between various ecosystems and sociocultural formations of the northern and southern Andes, the Pacific lowlands and Amazonia. The present STUDY EXPLORES AUSTRO LOJANO LINGUISTIC COMPOSITION THROUGH THE RESEARCH INTO THE ONOMASTICS OF the Chuquiribamba area. The preliminary results of morphological Segmentation of NON-Spanish PATRONIMYCS PROVE THE EXISTENCE OF TWO ETHNO-LINGUISTIC BRANCHES: KICHWA AND NON-KICHWA, INCLUDING in the latter forms that suggest connections not only with the extinct Puruhá and Cañari languages,

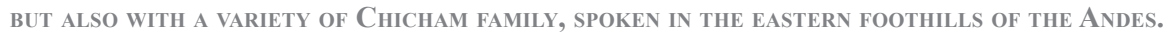

Keywords: Onomastics - Patronimycs - Pre-Quechuas languages - Puruhá - Cañari.

* Estudió Antropología, Lingüística y Estudios Culturales. Obtuvo su grado doctoral en Lingüística teórica en la Universidad de Ámsterdam (2008). Su especialidad son las lenguas indígenas del Ecuador, sobre las cuales ha realizado estudios descriptivos, sociolingüísticos y etnohistóricos. Actualmente se desempeña como profesor y director de investigación y posgrado en la Universidad de las Artes en Guayaquil. Correo electrónico: j.a.gomezrendon@uva.nl 


\section{Introducción}

71 presente estudio ofrece los resultados de una primera aproximación a la onomástica indígena del Austro lojano, en particular aquella de la parroquia de Chuquiribamba, declarada Patrimonio Cultural del Ecuador en 2013. En el marco de los estudios integrales de diseño para la rehabilitación y gestión de un área patrimonial en la parroquia de Chuquiribamba, se documentó información sobre los apellidos de sus pobladores, obteniéndose un total de 36 patronímicos que se enumeran a continuación:

\section{TABLA 1. Lista ONOMÁstica de ChUQuRIBAmBa}

\begin{tabular}{|l|l|l|l|}
\hline 1. Curipoma & 14. Bure & 27. Lima & 31. Valle \\
\hline 2. Viracocha & 15. Lasiche & 28. Yauri & 32. Cuenca \\
\hline 3. Sinche & 16. Alasiche & 29. Guayllas & 33. Loarte \\
\hline 4. Caraguay & 17. Cumbicus & 30. Guaya & 34. Remache \\
\hline 5. Pucha & 18. Saca & & 35. Ogoño \\
\hline 6. Huaca & 19. Guachanama & & 36. Jumbo \\
\hline 7. Morocho & 20. Sivisapa & & \\
\hline 8. Tambo & 21. Sivisaca & & \\
\hline 9. Pugo & 22. Tene & & \\
\hline 10. Puchaicela & 23. Viñamagua & & \\
\hline 11. Minga & 24. Michay & & \\
\hline 12. Angüisaca & 25. Hinchay & & \\
\hline 13. Buri & 26. Namicela & & \\
\hline
\end{tabular}

Junto a la mayoría de apellidos indígenas, se registraron varios de origen ibérico (en cursiva). El análisis de estos últimos no deja de presentar problemas de interpretación, pues curiosamente existirían formas locales equivalentes que podrían sustentar el origen indígena de tres de ellos². Sin embargo, su análisis queda postergado para otro estudio, buscándose en este conocer más bien la proveniencia etnolingüística de los patronímicos indígenas a través de un análisis morfológico sistemático.

\section{Consideraciones previas al análisis morfológico de la onomástica}

La onomástica es el estudio de los nombres, en particular de los nombres propios, sean estos de personas (antropónimos) o de lugares (topónimos). En la medida que busca explicar la composición y el origen de dichos nombres, la onomástica conlleva un carácter eminentemente etimológico y, en la misma medida, tiene una dimensión principalmente diacrónica. Esta

1 Convenciones tipográficas. A lo largo de este estudio conservamos la grafía actual de los patronímicos, excepto porque se escribirán en minúsculas y corchetes angulares cuando aparezcan dentro del texto. El guión simple después de un vocablo significa que es una raíz; si el guión se coloca antes, se trata de una terminación. Se utilizan barras inclinadas /.../ para representar formas fonológicas. En ocasiones se escribe la escritura estandarizada actual del vocablo kichwa luego de la forma patronímica tal como fue recogida. Finalmente, el corchete angular $(<)$ significa que el vocablo a su izquierda se origina en el vocablo de la derecha del signo.

2 En efecto, las listas de topónimos y patronímicos de Jijón y Caamaño (1940-1945) no sólo consignan los apellidos Jumbo, Remache y Ogoño entre la población indígena de la zona, sino que estos aparecen en ocasiones con grafías diferentes que sugieren un origen nativo: por ejemplo, <remache $>$ en lugar de <lima-che>, de base puruhá y terminación panzaleo. No es aventurado pensar que un patronímico nativo de pronunciación cercana a uno de origen ibérico se mimetizara en éste en el proceso de movilidad social y mestizaje de su portador. 
dimensión, a su vez, exige al analista una serie de consideraciones que deberá tomar en cuenta a fin de que las formas sometidas a segmentación sean las correctas.

La primera de estas consideraciones es que al haber sido recogidos en diversas épocas por diferentes autores con distinta formación y antecedentes, los datos onomásticos pueden presentar una variación importante. Esta variación dependerá de las convenciones ortográficas utilizadas por los recolectores según la época. Unas veces las variaciones ortográficas de un patronímico responderán a simples cambios en la convención escrita; otras veces, en cambio, se deberán a cambios operados en el sonido mismo de la palabra que quieren representar. Es de notar que los cambios fonéticos no son aleatorios y siguen reglas precisas. Así, por ejemplo, una palabra que empieza con un sonido velar sordo como $/ \mathrm{k} /$ eventualmente puede cambiar dicho sonido por uno de tipo fricativo sordo como $/ \mathrm{h} /$. Considerar la variación ortográfica y fonética es fundamental para el análisis puesto que, en muchos casos, dos nombres en apariencia disímiles pueden ser los mismos o bien tener el mismo origen, de tal suerte que resultan dos instancias (tokens) de un mismo patronímico (type).

La segunda consideración a tomar en cuenta es que los antropónimos, y en particular los patronímicos, se originan a menudo en topónimos, esto es, en nombres geográficos que señalan el lugar de proveniencia de los individuos o los colectivos, aun si dicho lugar ya no es su residencia. Este origen hace necesario que todo estudio de patronímicos esté acompañado de un estudio de topónimos dentro de la misma área de influencia.

La tercera consideración es que, desde un punto de vista lingüístico, los patronímicos llevan a menudo - aunque no necesariamente - ciertas marcas morfológicas distintivas. Estas marcas morfológicas generalmente se expresan en las terminaciones o finales de las formas patronímicas. Las terminaciones actúan como clasificadores que distinguen los patronímicos de otros nombres propios y les asignan una filiación etnolingüística específica. Esta es la razón para que todo estudio onomástico incluya la identificación de las marcas finales. En ocasiones, éstas pueden ser aún más importantes, desde un punto de vista clasificatorio, que las mismas raíces o bases que componen los patronímicos, las cuales han de estudiarse íntegramente solo después de haber identificado las primeras.

\section{Análisis morfológico de los patronímicos de la parroquia de Chuquiribamba}

Una vez homologada la base de datos de acuerdo con los criterios señalados en la sección anterior, el análisis lingüístico de los patronímicos se desarrolló en cuatro pasos: a) identificación de formas patronímicas kichwas y de posible origen híbrido; b) segmentación morfológica de patronímicos no-kichwas en raíces y terminaciones; c) cotejo de terminaciones no-kichwas en fuentes toponímicas y antroponímicas; y d) cotejo de patronímicos con fuentes toponímicas y antroponímicas disponibles a fin de identificar posibles filiaciones etnolingüísticas.

De los treinta patronímicos resultantes de sustraer los de origen ibérico de la lista original, se procedió a separar los de origen kichwa por la facilidad de su identificación. Se obtuvo así once vocablos de origen quechua/kichwa. Los diecinueve restantes se adscribieron por defecto al grupo de patronímicos no-kichwas, incluyendo tres de composición híbrida (kichwa-puruhá/ cañari, kichwa-chicham ${ }^{3}$, marcados con un asterisco).

Las formas kichwas no dejan lugar a dudas sobre su origen etnolingüístico salvo $<$ lima $>$. Para esta se postulan dos posibles orígenes: uno es el hidrónimo quechua $<$ rimaq $>$, del cual se origina el nombre de la capital peruana, convertido en $<$ limaq $>$ debido al lambdacismo de la pronunciación en las variedades quechuas costeñas $(\mathrm{r}>1)$; otro origen es la terminación puruhá $<$ lema $>$. Esta última interpretación, sin embargo, requiere un cambio categorial en virtud del cual el morfema final puruhá-cañari se hubiera convertido en una forma independiente que no requiera a su vez

3 Optamos aquí por el etnónimo-glotónimo chicham, de reciente cuño y difusión en los círculos lingüísticos y antropológicos, en lugar de su equivalente "jibaroano", por las connotaciones despectivas de este último. 
de terminación. La probabilidad de esta transcategorización es directamente proporcional a la transparencia semántica de la forma en cuestión. Sin embargo, al no conocer su significado - a más de ser un clasificador patronímico que aparece recurrentemente en apellidos - creemos que el primer origen es el más acertado porque no tiene ningún condicionamiento y preserva incluso la vocal original del hidrónimo /i/4.

TABLA 2. ClasificaCión GENERAL DE PATRONÍMICOS DE ORIGEN KICHWAS Y POSIBLES HíBRIDOS

\begin{tabular}{|c|c|c|c|}
\hline \multicolumn{2}{|c|}{ Patronímicos kichwas/quechuas } & \multicolumn{2}{|c|}{ Patronímicos no-kichwas } \\
\hline Ortográfica & Fonética & Ortográfica & Fonética \\
\hline 1. Morocho & [moročo] $<$ [muruču $]$ & 1. Angüisaca & [angwisaka] \\
\hline 2. Pucha & [puča] & 2. Buri & [buri] \\
\hline 3. Curipoma & {$[$ kuripoma $]<[$ kuripuma $]$} & 3. Bure & [bure] \\
\hline 4. Tambo & {$[$ tambo] $<[$ tambu $]$} & 4. Caraguay & [karaway] \\
\hline 5. Lima (=lema?) & {$[$ lima $]<[$ rimak $]$} & 5. Cumbicus & [kumbikus] \\
\hline 6. Yauri & [yawri] & 6. Guachanama & [gwačanamá] \\
\hline 7. Huaca & [waka] & 7. Hinchay & [inčay] \\
\hline 8. Sinche & {$[$ sinče $]<[$ sinči $]$} & 8. Lasiche & [lasiče] \\
\hline 9. Viracocha & [birakoča] $<$ [wirakuča] & 9. Alasiche & [alasiče] \\
\hline 10. Minga & [minga] & 10. Michay & [mičay $]$ \\
\hline 11. Guaya & [gwaya] $<$ [waya] & 11. Namicela & [namisela] \\
\hline 12. Guayllas & [gwaKas] & 12. Puchaicela* & [pučaisela] \\
\hline & & 13. Pugo & [pugo] \\
\hline & & 14. Saca & [saca] \\
\hline & & 15. Sivisaca & [sißisaka] \\
\hline & & 16. Sivisapa* & [sißisapa] \\
\hline & & 17. Tene & [tene] \\
\hline & & 18. Viñamagua* & [binamagwa] \\
\hline
\end{tabular}

Desde un punto de vista morfológico, los patronímicos de origen kichwa se pueden clasificar en formas simples y formas compuestas, siendo las primeras las más frecuentes. Así, mientras las formas $<$ tambo $>$ y $<$ sinche $>$ son indivisas, las formas $<$ curipoma $>$ (kuri-puma) y $<$ viracocha $>$ (wira-kucha) comprenden dos lexemas cada una. Estas últimas están asociadas a la esfera inca y corresponden a la variedad del quechua cuzqueño utilizada en la administración y la religión. Las formas kichwas simples, por su parte, se clasifican en dos grupos según la variedad dialectal a la que pueden adscribirse: un grupo está formado por las voces $<$ minga $>$ (minka), $<$ morocho $>$ (muruchu), $<$ pucha $>$ (pucha), $<$ sinche $>$ (sinchi) y $<$ tambo $>$ (tanpu), comunes en las variedades dialectales del kichwa ecuatoriano; los seis patronímicos restantes son formas correspondientes a variedades quechuas del centro y sur del Perú, aunque para algunos casos no podemos descartar orígenes alternativos. Así, el lexema <guaya $>$ (waya) es común en los dialectos quechuas de Ancash, Ayacucho, Cuzco, Huancavelica y Huanca, aun cuando aparece también como regionalismo del kichwa azuayo con el significado de "remolino de pelo en la frente" (Torres

4 Mientras las vocales medias (/e/, /o/) que presentan patronímicos como $<$ tambo $>$ o $<$ sinche $>$ se deben a una castellanización del sistema vocálico kichwa $(/ \mathrm{a} /, / \mathrm{i} /, / \mathrm{u} /)$, las formas originarias del cuzqueño, como $<$ curipoma $>$ y

$<$ viracocha $>$, mantienen la vocal media posterior $(/ \mathrm{o} /)$. 
Fernández de Córdova, 2002 II: 91), por lo que no se puede excluir un posible origen pre-inca, posiblemente cañari. Por otro lado, sin ser originaria de las variedades kichwas ecuatorianas, la voz $<$ huaca $>$ (sic), gracias a su connotación religiosa, llegó a difundirse pronto en los Andes septentrionales, desde las variedades del centro-sur peruano, donde significa "entierro", pese a que su etimología original es "apertura" o "hendidura". En cualquier caso, la presencia de este patronímico muy probablemente está relacionada con el quechua cuzqueño, como es el caso de las formas compuestas $<$ curipoma $>\mathrm{y}<$ viracocha $>$.

Por constituir la mitad del acervo patronímico de Chuquiribamba y ofrecer su adscripción lingüística varias dificultades, reservamos la discusión de las voces no-kichwas para la última sección, luego de presentar el análisis morfológico de las raíces y terminaciones y ensayar su clasificación según los registros toponímicos y antroponímicos disponibles.

\section{Segmentación morfológica de los patronímicos no-kichwas}

Cuatro de los diecinueve patronímicos no-kichwas se agruparon en dos parejas de alomorfos (buri/bure, lasiche/alasiche), con lo cual se redujeron a diecisiete los tipos patronímicos diferenciados. Un análisis morfológico de las formas no-kichwas permitió a su vez identificar nueve terminaciones, a las cuales podemos asignar una distribución geográfica y, a partir de ella, sugerir posibles filiaciones etnolingüísticas.

\begin{tabular}{|c|c|}
\hline Raíces & Terminaciones \\
\hline Alasi- $\sim$ Lasi- & -ay \\
\hline Angüi- & -guay \\
\hline Buri- $\sim$ Bure- & -cus \\
\hline Cara- & -cela \\
\hline Cumbi- & -che \\
\hline Guachana- & -magua \\
\hline Hinch(a)- & -ma \\
\hline Mich(a)- & -saca \\
\hline Nami- & -sapa \\
\hline Puchai- & \\
\hline Pugo & \\
\hline Sivi- & \\
\hline Tene & \\
\hline Viñ- & \\
\hline
\end{tabular}

La terminación $<$-ay $>$ aparece en tres patronímicos en tanto que $<$-cela $>$ y $<$-saca $>$ ocurren en dos patronímicos cada una. El resto de terminaciones ocurre solamente una vez. Solo una forma aparece como raíz y terminación a la vez $(<$ saca- $>,<$-saca $>)$.

Las raíces presentan una forma silábica regular (CVCV). Gracias a su estructura silábica, es posible reconocer el origen kichwa de varias de ellas, aunque en ocasiones no se pueda conocer el lexema específico del que provienen: así, <guacha $>$ proviene de wacha-/wakcha, y $<$ viña $>$, de wiña-/wiñak. Nótese que las formas patronímicas $<$ buri $>/<$ bure $>$, $<$ pugo $>$, y $<$ tene $>$ no son segmentables en ningún caso. La última raíz, sin embargo, aparece a menudo con la terminación <-cela> en Chimborazo, Cañar y Azuay. En otros casos la estructura silábica resulta más compleja y solo permite una división aproximada, desconociendo como desconocemos los 
cánones silábicos de la lengua originaria. Así, para los patronímicos $<$ michay $>\mathrm{y}<$ hinchay $>$, asumimos la posibilidad de una vocal final/-a/ en la última sílaba de la raíz, la misma que se fusiona con su homóloga al sufijarse la terminación $<$-ay $>$.

\section{Fuentes toponímicas y antroponímicas utilizadas}

La selección de fuentes utilizadas para el cotejo responde a un criterio areal, según el cual existiría una filiación etnolingüística de los patronímicos más allá de la zona geográfica de estudio (provincia de Loja), incluyendo toda la región austral (Cañar y Azuay) e incluso la Sierra central (Cotopaxi, Tungurahua y Chimborazo), como sugiere el análisis previo de las terminaciones.

Las fuentes corresponden a varias de las listas que aparecen en el segundo y el tercer volumen de El Ecuador Interandino y Occidental (Jijón y Caamaño, 1940-1945), específicamente: lista Cañari-A, "Topónimos y apellidos cañari" (1941, II: 7-35); lista Cañari-B, "Nuevos materiales para el estudio del Cañari (1759)" (1943, III: 5-141); lista Loja-A, “Algunos nombres patronímicos de la Provincia de Loja" (1940, II: 48-53); lista Loja-B, "Topónimos de la Provincia de Loja (1942)" (1943, III: 146-154); y lista Loja-C, "Patronímicos de Loja (1759)" (1943, III: 5-155170). La listas Loja-C y Cañari-B fueron compiladas por Jijón y Caamaño a partir de un proceso de 278 páginas preparado por el corregidor de Cuenca en 1759 a pedido del presidente de la Real Audiencia, donde le informa, entre otras cosas, sobre la población tributaria del corregimiento. Las listas restantes son de colecta más reciente pero no dejan de ser importantes para un cotejo diacrónico con las primeras. Se han consultado además las listas toponímicas y patronímicas "Nombres geográficos y patronímicos de panzaleo" [Lista Panzaleo-A] (1940, I: 295-387) y "Nombres patronímicos y geográficos que sólo se encuentran al norte del Perú" [Lista Puruhá-A] (1940, I: 422-441).

Entre las fuentes de carácter secundario se cuentan, en primer lugar, la valiosa compilación del Diccionario Toponímico de Paz y Miño (1961-1964), que comprende un total de 10.196 topónimos y antropónimos con su glosa y ubicación geográfica. El uso de esta fuente se vio facilitado por su digitalización a través de una herramienta de software lexicográfico que permite búsquedas rápidas. Otra fuente secundaria constituye el estudio no publicado de Belote y Belote, "Non-imperial toponymic element distribution in the Ecuadorian Highlands" (1999), donde los autores realizan un mapeo de terminaciones no-kichwas según la frecuencia con que aparecen en la cartografía 1:50.000 preparada por el IGM en los años noventa para la Sierra del Ecuador.

\section{Análisis de las terminaciones no-kichwas en los patronímicos de Chuquiribamba}

De las nueve terminaciones identificadas, /-ay/ muestra una amplia dispersión en topónimos y antropónimos de las provincias de Cañar, Azuay y el norte de Loja, pero también en la Costa, en las provincias de Guayas y El Oro. La terminación parece ocurrir en la zona con otras parcialmente homófonas como/-way/y/-kay/, sugiriendo un origen etnolingüístico común. De acuerdo con Jijón y Caamaño, la final <-ay> se encuentra en patronímicos y topónimos de las esferas de influencia puruhá y cañari, pero también en el norte del Perú e incluso al sur de los departamentos peruanos de Lima y Junín (Jijón y Caamaño, 1940, II: 534). Paz y Miño confirma esta distribución para el Ecuador y consigna más de trescientos topónimos con este morfema desde el sur de la provincia de Chimborazo hasta el extremo meridional de Loja (Cfr. Paz y Miño, 1961-1964). Belote y Belote, por su parte, mapean la distribución del homófono <-cay> en las provincias de Cañar, Azuay y Loja, incluyendo la zona de Saraguro, de lo cual concluyen que debió pertenecer a la zona de influencia cañari pero no a la de influencia palta, ubicada más al sur, a la que corresponden las terminaciones $<$-numa $>$ y $<$-mine $>$ (Belote y Belote, 1999).

Las terminaciones $<$-saca $>$ y $<$-cela $>$ presentan una distribución menos amplia que $<$-ay $>$, pues se encuentran exclusivamente en las provincias de Cañar, Azuay y Loja. Jijón y Caamaño 
encuentra más de treinta patronímicos terminados en <-cela $>$ en Cañaribamba y Loja y afirma que esta terminación, al igual que <-saca>, aparece exclusivamente en patronímicos (Jijón y Caamaño, 1940, I: 423-436). No obstante, es posible encontrar ambas formas en nombres geográficos, ya sea como terminaciones o como raíces: así, por ejemplo, Paz y Miño identifica $<$ ashacela $>$, <celata $>$ y $<$ cela $>$, tres nombres geográficos de la zona de Sigsig, Girón y el norte de la ciudad de Loja, en la zona de influencia cañari (Paz y Miño 1961-1964). La terminación $<$-saca>, por su parte, aparece en el diccionario de Paz y Miño en ocho nombres geográficos de Cañar, Loja, Bolívar y Ambato (vide Sala-saca); incluso como raíz en los topónimos <sacá-ma $>$ $\mathrm{y}<$ saca-huán $>$. Nótese a propósito la similitud fonética de la terminación $<$-aca $>$, que al igual que $<$-saca $>$ encaja muy bien en la esfera de influencia puruhá-cañari y sugiere que se trata de dos formas en distribución complementaria.

El caso de la final <-sapa> es controvertido. A primera vista parece de origen kichwa, lengua en la cual sirve de aumentativo en la formación de adjetivos superlativos. Sin embargo, su cercanía a la forma <-shapa> sugiere que se trata de dos alófonos, más todavía cuando ambas se distribuyen en el norte y el noroeste de Loja, en la mitad meridional de Cañar y en el occidente de la provincia del Azuay. De acuerdo con Belote y Belote (1999), la forma <-shapa> tendría origen cuzqueño y su semántica sería la de "único". Consideramos que esta interpretación no es correcta. No sólo no existe un alomorfo semejante de $/$-sapa $/{ }^{5}$ sino que la única forma de comprobar su significado es a partir de su asociación con el aumentativo. Por lo demás, no deja de ser curioso que esta terminación no haya sido identificada por Jijón y Caamaño, aun cuando ocurra en varios ítems de sus listas toponímicas. En el diccionario toponímico de Paz y Miño aparece en doce nombres geográficos, incluyendo, entre otros, el sitio de $<$ jati-shapa $>$ al sur del pueblo de Chuquiribamba y el de $<$ llui-shapa $>$ al este del pueblo de Manú; los ríos <paqui-shapa $>$ y $<$ udu-shapa $>$, afluentes ambos del Leohuaico; la elevación de <sal-shapa $>$ al noroeste de Santa Isabel, en el Azuay; y la zona arqueológica de $<$ tacal-shapa $>$, en Cañar. Hechas estas consideraciones, proponemos que la terminación $<$-sapa $>$ no es de origen kichwa sino pre-kichwa y corresponde, como las anteriores, a la esfera de influencia cañari.

La terminación <-che> - posiblemente en variación libre con su alomorfo <-chi> presenta un problema de interpretación asociado con su ubicuidad en la geografía ecuatoriana. En efecto, esta final se encuentra dispersa a lo largo de los Andes, desde Imbabura hasta Loja, pero también aparece en las vertientes occidentales y orientales de la cordillera. Más todavía, Jijón y Caamaño sugiere que <-chi-> ocurre no solo como final sino también como raíz y elemento intercalado (Jijón y Caamaño, 1940, III: 271). Aunque la amplitud de su distribución deja abierta la puerta a varios orígenes etnolingüísticos posibles, su concentración en nombres geográficos de Imbabura, Pichincha y Cotopaxi sugiere una asociación específica. En efecto, $<$ chi $>$ aparece en Imbabura sobre todo en topónimos de la vertiente andina occidental; en Pichincha, principalmente en su mitad meridional; y en Cotopaxi, en el centro y el occidente de la provincia. Fue esta concentración la que llevó a Jijón y Caamaño a postular como su origen el área de influencia panzaleo, donde, según este autor, se hablaba una lengua distinta del cara (al norte) y el puruhá (al sur).

La existencia de una lengua panzaleo ha sido desechada por algunos autores, que la desconocen como entidad lingüística independiente (Paz y Miño, 1940-1942; Pérez, 1962: 255; Costales y Peñaherrera de Costales, 2002: 93). Según ellos, el panzaleo nunca existió y la lengua de donde provienen los topónimos de la zona no es otra que el tsa'fiki, lengua en la cual la terminación <-chi> corresponde efectivamente a un morfema locativo. Aunque el parentesco del tsa'fiki con el cha'palaa y el awapit - todas de la familia barbacoana - ayuda a explicar la difusión serrana y costeña de nombres geográficos y patronímicos asociados con este origen

5 Existe, sin embargo, el alomorfo /-supa/ que aparece en topónimos en la esfera de influencia cañari tales como $<$ llivisupa $>$ 
etnolingüístico, es difícil dar cuenta de su presencia en el Austro. En este caso nos parece acertado explicar la presencia de esta final en la onomástica de Chuquiribamba bien por la llegada tardía de mitimaes barbacoanos trasplantados al Austro bajo el dominio inca, o bien por la existencia de una población de indios forasteros de origen barbacoano que se formó en tiempos coloniales, algo del todo probable si se toma en cuenta la movilidad de los grupos colorados del piedemonte andino occidental en tiempos coloniales (Cfr. Gómez Rendón, 2015) 6 .

Son tres las terminaciones de las cuales nos queda rastrear su origen, a saber: <-cus>, $<$-ma $>$ y $<$-magua $>$. La primera de estas finales es de escasa presencia en las fuentes (Jijón y Caamaño, 1940; Paz y Miño, 1961-1964). Es posible que se encuentre en variación libre con la final <-cos>, mejor representada en los datos toponímicos. En efecto, Paz y Miño documenta para la variante <-cus> los siguientes nombres geográficos: <macus $>$, forma antigua asociada con la actual ciudad de Macas; <panicús>, nombre de una antigua encomienda en el piedemonte oriental de la actual provincia del Azuay en su límite con Morona Santiago; y $<$ picús $>$, hidrónimo de un afluente del río Metzanguima cerca de su desembocadura en el Makuma. Los nombres con final <-cos $>$ son algo más frecuentes y ocurren en algunos casos en el piedemonte andino oriental: <alapicos $>/<$ arapicos $>$, emparentado posiblemente con el hidrónimo < picús>, se registra en el río Palora, provincia de Morona Santiago; <guambucos> es el nombre de una antigua parcialidad del Alto Chinchipe; <tricos $>$, el de una parcialidad al oriente de Sigsig; $\mathrm{y}<\mathrm{zacos}>$, el de una antigua encomienda al este del Azuay. Al mismo tiempo, no deja de ser curioso que se encuentren nombres geográficos con la misma terminación hacia la vertiente occidental andina: por ejemplo, $<$ nutcos $>$, nombre de una quebrada de Gualleturo en dirección a Naranjal; <shucos $>$, nombre de un monte al oeste del pueblo de Piñas. Si tomamos en cuenta esta distribución, es posible que se trate de una terminación de origen chicham o puruhá-cañari. La etnohistoria de la región de Chuquiribamba sugiere que el patronímico < cumbicus> puede ser más bien de origen palta o malacato, correspondiente a los llamados jíbaros de montaña (Casevitz et al., 1988: 210). Corrobora esta interpretación la existencia del topónimo < cumbicus $>$ en el distrito de Pacaipamba, provincia de Ayabaca, en el noreste del departamento peruano de Piura, zona que se encuentra en los límites del territorio palta (Cfr. Ibíd.: 208).

En cuanto a la final<-má>, Jijón y Caamaño la agrupa dentro de las que aparecen en el Austro ecuatoriano pero no en el norte del Perú, con lo cual su distribución geográfica se asemeja a $<$-cela $>$ y $<$-saca $>$, tratadas al inicio de esta sección. Este autor identifica veintinueve nombres con esta terminación, entre topónimos (8) y patronímicos (21). Diez patronímicos provienen de la zona de Cañaribamba; cuatro de la zona de Licán en Chimborazo; dos del sur de Cotopaxi; y cinco de la provincia de Loja. Los topónimos con igual terminación se encuentran tres en Loja, tres en el extremo meridional de Morona Santiago (zona de Gualaquiza), y dos en la costa (zona de Tumbes). El topónimo < guachanamá $>$ aparece como el nombre de un lugar cerca de Célica (Jijón y Caamaño, 1940, I: 440). Los datos disponibles no permiten distinguir claramente entre las terminaciones $<$-ma $>$ y $<$-nama $>$. Ésta última, junto con $<$-anga $>$ y $<$-numa $>$, es común en varios topónimos del territorio palta y ha sido asociada con lenguas de la familia chicham. Así, Gnerre (1975) considera que <-numa> y $<$-nama $>$ corresponden al marcador shuar de caso locativo /-num/ y /nam/ mientras Torero considera que <-namá> está más cerca del vocablo /namáka/, 'río' en lengua aguaruna (Torero, 1993).

6 Que el origen de la terminación <-che $>$ sea la sierra central podría corroborarse por la base $<$ ala->, que entra en la formación del patronímico <alasiche> y que, según Jijón y Caamaño, es común para la zona de influencia panzaleo (1940, III: 209). No obstante, la raíz < alasi-> también guarda un gran parecido con el topónimo cañari $<$ alausí $>$. En este caso, se podría plantear el origen híbrido de la forma patronímica, con una raíz de origen cañari y una terminación de origen barbacoano. Recordemos a propósito que existen formas híbridas con raíces kichwas y terminaciones no-kichwas. Éstas entran en la formación de patronímicos cumpliendo la función de clasificadores: por ejemplo, $<$ sisalema $>$, donde la raíz $<$ sisa- $>$ es de claro origen kichwa (sisa, 'flor') mientras la terminación proviene del puruhá. 
Sopesando toda la evidencia, la terminación <-ma> podría tener dos orígenes diferentes, uno puruhá-cañari y otro chicham (palta), de suerte que los topónimos que la llevan y se encuentran en las provincias de Chimborazo y Cañar pertenecerían al primero, y aquellos que se encuentran en Loja, Morona Santiago y la zona de Tumbes se adscribirían al segundo.

Por último, la final <-magua> aparece solo en varios nombres geográficos de la hoya amazónica occidental: así, <omagua > / <omaguas >, nombre de una hacienda en la orilla izquierda del río Marañón, nombre de varias islas en este mismo río, y nombre primitivo de la región comprendida entre el Tigre y el Napo; y <yurimaguas $>7$, nombre de una antigua parcialidad del bajo Santiago, actual ciudad del norte peruano, capital de la provincia de Alto Amazonas (Paz y Miño, 1961-64). Esta distribución sugiere una filiación con grupos etnolingüísticos chicham cercanos al piedemonte oriental de los Andes. A ello se debe quizás la existencia del patronímico híbrido < viñamagua $>$, compuesto de la raíz kichwa $<$ wiña- $>$ y la terminación $<$-magua $>$.

\section{Análisis de los patronímicos no-kichwas según su distribución en las fuentes}

El siguiente cuadro enlista los patronímicos no-kichwas (columna izquierda) según aparecen en una o más de las siete listas mencionadas (cf. supra), con su explicación y referencia respectiva (columna derecha). En caso de que la ortografía del original sugiera una pronunciación diferente, aparece entre corchetes angulares y en paréntesis. El siguiente cuadro consigna solamente una muestra de casos para varios de los patronímicos que aparecen en más de una ocasión en las listas.

\begin{tabular}{|c|c|}
\hline Patronímicos indígenas & Fuente \\
\hline 1. Angüisaca & $\begin{array}{l}\text { - Lista Cañari-A: Núm 26, pg. 8, "apellido" } \\
\text { - Lista Loja-C: Núm 496, pg. 161, "Puruha-Mochica. Vide V. c. } \\
\text { Números } 132 \text { y } 1284 " \text { (Villa de Zaruma, cacique don Francisco } \\
\text { Galves) (<angisaka>) } \\
\text { - Lista Cañari-B: Provincia de Cuenca. Pueblo de Azogues. } \\
\text { Parcialidad de Maxco. Cacique don Esteban Zuka, pg. } 24 \\
\text { (<angisaka }>\text { ) }\end{array}$ \\
\hline 2. Buri $\sim$ Bure & $\begin{array}{l}\text { - Lista Cañari-A: Núm 128,pg. 10, "apellido" } \\
\text { - Lista Cañari-A: Núm 129, pg. 10, "Lugar de la parroquia } \\
\text { de Sigsig y en la parroquia de El Oriente del Cantón Paute" } \\
\text { (<burin }>\text { ) } \\
\text { - Lista Cañari B: Provincia de Cuenca. Pueblo de Azogues. } \\
\text { Parcialidad de Puezar. Cacique don Bernardo Karchipudlla, pg. } \\
24 \text { "Cañari, Núm. 128". }\end{array}$ \\
\hline 3. Caraguay & $\begin{array}{l}\text { - Lista Loja-C: Núm 459, pg. 160, "Puruha-Mochica. Vide V. c. } \\
\text { Números } 335 \text { y } 13 \text { (<karuay }>)\end{array}$ \\
\hline 4. Cumbicus & $\begin{array}{l}\text { - Lista Loja-C: Núm 598, pg. 165, "Panzaleo y Puruhá- } \\
\text { Mochica" (pueblo de Gonzanáma, cacique don Tomás Narváez) } \\
(<\text { kumbikuz }>\text { ) }\end{array}$ \\
\hline
\end{tabular}

7 Nótese, a propósito, que el topónimo $<$ yurimagua(s) $>$ es segmentable de manera transparente en $<$ yuri- $>$ y $<$ magua $>$ y que la raíz es un alolexo de uno de los patronímicos documentados en Chuquiribamba, <yauri $>$. 


\begin{tabular}{|c|c|}
\hline 5. Curipoma & $\begin{array}{l}\text { - Lista Loja-A: Núm 30,pg. 49, "apellido de Santiago" (<kuripoma }>\text { ) } \\
\text { - Lista Loja-C: Núm 360, pg. 157, "quechua" (Parroquia de San } \\
\text { Juan del Valle, cacique don Blas Benites) < poma }> \\
\text { - Lista Loja-C: Núm 362, pg. 157, "quechua" (Parroquia de San } \\
\text { Juan del Valle, cacique don Blas Benites) < kuri }> \\
\text { - Lista Cañari-C: Provincia de Alausí. Parcialidad de Guasuntos. } \\
\text { Cacicazgo de don Bernardo Pingullo, pg. 9. (<pumakuri }>\text { ) }\end{array}$ \\
\hline 6. Guachanama & $\begin{array}{l}\text { - Lista Loja-B: Núm 76, pg. 148, "Puruhá-Mochicha. Vide V. c. } \\
\text { Nos. } 1550 \text { y } 1860 " \text { (<wachanamá>) } \\
\text { - Lista Loja-B: Núm 133, pg. } 150 \text { "Puruhá-Mochica. Vide Supra } \\
\text { No. 76" (<wachanamá>) }\end{array}$ \\
\hline 7. Guaya & $\begin{array}{l}\text { - Lista Cañari-A: Núm 452, pg. 18, "Lugar de Paute y de Jadán" } \\
(<\text { wayán }>)^{8} \text {. }\end{array}$ \\
\hline 8. Guayllas & $\begin{array}{l}\text { - Lista Loja-A: Núm. 94, pg. 50, “apellido de Santiago" } \\
\text { - Lista Cañari-A: Núm 403, pg. 17, “apellido" (<waillas>) }\end{array}$ \\
\hline 9. Hinchay & $\begin{array}{l}\text { - Lista Cañari-A: Núm 403,pg. 17, "quebrada de Ludo" (< } \text { güi-chay }>\text { ) } \\
\text { - Lista Cañari-A: Núm 938, pg. 29, "apellido" (<siabi-chay }>) \\
\text { - Lista Loja-A: Núm 38, pg. 49, "apellido de San Juan Bautista } \\
\text { del Valle de Loja" }(<\text { kinche }>)\end{array}$ \\
\hline 10. Huaca & - Lista Loja-A: Núm. 95, pg. 50, “apellido de Santiago”. \\
\hline 11. Lasiche $\sim$ Alasiche & $\begin{array}{l}\text { - Lista Loja-C: [voz de la lengua rabona, posiblemente de la } \\
\text { familia chicham] pg. } 169 \text { 'caimito' }(<\text { asishe }>) \\
\text { - Lista Panzaleo-A: Núm } 175 \text {, pg. } 300 \text {, “apellido del ayllo de los } \\
\text { Chumaquíes de Pelileo" (<alaicha }>\text { ) }\end{array}$ \\
\hline 12. Lima & $\begin{array}{l}\text { - Lista Loja-A: Núm. 113, pg. 50, “apellido del Egido de Loja” } \\
\text { - Lista Loja-B: Núm. 163,pg. 151, "Puruhá-Mochica, lema, ¿Post } \\
\text { hispánico?" }\end{array}$ \\
\hline 13. Michay & • Lista Loja-A: Núm. 125, pg. 51, “apellido de Santiago". \\
\hline 14. Minga & $\begin{array}{l}\text { - Lista Loja-A: Núm. 126, pg. 51, “apellido de Santiago" } \\
\text { - Lista Loja-C: Núm. 434, pg. 159, "quechua” (Pueblo de } \\
\text { Saraguro, cacique don Luis Lozano) }\end{array}$ \\
\hline 15. Morocho & $\begin{array}{l}\text { - Lista Loja-C: Núm 339, pg. 157, “quechua” (Parroquia San Juan } \\
\text { del Valle, cacique Francisco Benítez). }\end{array}$ \\
\hline 16. Namicela & - Lista Puruhá-A: (3) Final cela, pg. 427 (<namcela>) \\
\hline 17. Pucha & $\begin{array}{l}\text { - Lista Cañari-B: } \\
\text { - Provincia de Alausí. Indios forasteros a cargo de don Félix } \\
\text { Ramírez, pg. 7, "Panzaleo?” } \\
\text { - Provincia de Alausí. Pueblo de Tixán. Parcialidad de Yuyautte, } \\
\text { del cacique don Baltazar Lazovikay, pg. } 14 .\end{array}$ \\
\hline
\end{tabular}

8 Guaya aparece citado asimismo en la concesión de una encomienda que data de 1540, dentro de la "provincia de los Cañares de Hurinsaya" (Caillavet, 2000: 227). 


\begin{tabular}{|c|c|}
\hline 18. Puchaicela & $\begin{array}{l}\text { - Lista Cañari-B: Provincia de Alausí. Pueblo de Tixán. } \\
\text { Parcialidad de Chawalán del Cacique don Mateo Lazo, pg. } 13 \\
(<\text { puchaizela }>)\end{array}$ \\
\hline 19. Pugo & $\begin{array}{l}\text { - Lista Loja-C: Núm 318, pg. 156, "castellano" (Ciudad de Loja, } \\
\text { Parroquia San Sebastián, cacique don Nicolás Espadero) (<puga }>\text { ) } \\
\text { - Lista Loja-C: Núm 324, pg. 156, "castellano" (Ciudad de Loja, } \\
\text { don Enrique Tarki Cacique) (<puga }>\text { ) }\end{array}$ \\
\hline 20. Saca & $\begin{array}{l}\text { - Lista Cañari-B: Num 833, pg. 27, “apellido" (<saka }>\text { ) } \\
\text { - Lista Loja-C: Núm 424, pg. 159, "Puruha-Mochica. Vide V. c. } \\
\text { Núm 1284" (Pueblo de Saraguro, cacique don Francisco Medina) }\end{array}$ \\
\hline 21. Sinche & $\begin{array}{l}\text { - Lista Loja-C: Núm 490,pg. 161, "quechua" (Pueblo de Pagcha, } \\
\text { cacique don Hermenegildo Buele) ( }<\text { sinchi }>\text { ) }\end{array}$ \\
\hline 22. Sivisaca & $\begin{array}{l}\text { - Lista Cañari-B: Provincia de Cuenca. Pueblo de Azogues. } \\
\text { Parcialidad de Wangra. Cacique don Juan Rivera Bohorquez, } \\
\text { pg. } 25 \text { (<zivisaka }>\text { ) } \\
\text { - Lista Loja-C: Núm 521, pg. 162, "Puruhá-Mochica. Vide V. } \\
\text { c. Números } 924 \text { y 1284” (pueblo de Katakocha, cacique don } \\
\text { Calisto Criollo) (<vivisaka }>\text { ) } \\
\text { - Lista Cañari-B: Pueblo de Azogues. Indios forasteros residentes en } \\
\text { Sajeo, Cacique don Sebastián Sinin, pg. 45, "apellido" (<llivisaka }>\text { ) } \\
\text { - Lista Panzaleo-A: Núm 2959, Vol. 1, pg. 375, "apellido de } \\
\text { Isilinví e Izamba (<llivisaka }>\text { ) }\end{array}$ \\
\hline 23. Sivisapa & $\begin{array}{l}\text { - Lista Cañari-B: Provincia de cuenca. Pueblo de Azogues. Indios } \\
\text { Oriundos, pg. } 23(<\text { llivisupa }>)\end{array}$ \\
\hline 24. Tambo & - Lista Loja-B: Núm 100, pg. 149, "Quechua" \\
\hline 25. Tene & $\begin{array}{l}\text { - Lista Loja-A: Núm. 45, pg. } 49 \text { "apellido de San Juan Bautista } \\
\text { del Valle de Loja" } \\
\text { - Lista Cañari-B: Núm 1027, pg. 32, "apellido" } \\
\text { - Lista Loja-C: Núm 416, pg. 159, "Puruha-Mochica. Vide V. c. } \\
\text { Núm. 608" (Pueblo de Saraguro, cacique don Francisco Medina) }\end{array}$ \\
\hline 26. Viñamagua & $\begin{array}{l}\text { - Lista Loja-A: } \\
\text { - Núm 91, pg. 50, “apellido de Santiago" } \\
\text { - Núm 90, pg. 50, “apellido de San Juan Bautista del Valle de } \\
\text { Loja” (<viñamau >) } \\
\text { - Lista Cañari-B: Provincia de Cuenca. Pueblo de Sigsig. } \\
\text { Parcialidad de Duma. Cacique don Lorenzo Duma, pg. } 39 \\
(<\text { tenemawa>). }\end{array}$ \\
\hline 27. Viracocha & $\begin{array}{l}\text { - Lista Loja-C: Núm 506, pg. 162, “quechua” (villa de Zaruma, } \\
\text { cacique don Francisco Galves) (<virakocha }>\text { ) }\end{array}$ \\
\hline 28. Yauri & $\begin{array}{l}\text { - Lista Loja-C: Núm 451, pg. 160, "Puruha-Mochica. Vide V. c. } \\
\text { 1120" (Pueblo de Manu, cacique don Agustín Cuenca) } \\
\text { - Lista Cañari-B: Provincia de Alausí. Parcialidad de Guasuntos. } \\
\text { Cacicazgo de don Bernardo Pingullo, pg. } 8 .\end{array}$ \\
\hline
\end{tabular}


Un balance general del cotejo con las fuentes onomásticas demuestra que las dos terceras partes de los patronímicos de Chuquiribamba no solo aparecen en listas recogidas el siglo pasado sino también en aquellas elaboradas a partir del documento de 1759 para todo el Corregimiento de Cuenca (cfr. supra). Pero además, el cotejo nos enseña que su presencia no se reduce a esta parroquia lojana, ni siquiera a toda la provincia o la región austral. En efecto, para varios patronímicos es posible demostrar su pertenencia a un área geográfica que abarca toda la Sierra centro-sur e incluso las vertientes occidentales y orientales de la cordillera andina.

Sin embargo, no sólo que la distribución no es uniforme para todo el corpus sino que cuatro patronímicos no fueron constatados. Dos de ellas son $<$ lasiche $>$ y su alolexo $<$ alasiche $>$. Es interesante que ambas formas guarden similitud con el patronímico panzaleo $<$ alaicha $>$, que corresponde a uno de los ayllus de la zona de Pelileo. Más interesante es, a nuestro juicio, su cercanía fonética con chicxi 'sapodilla', uno de los escasos fitónimos que se conservan de la extinta lengua rabona, hablada por jíbaros montañeses en las estribaciones orientales de la cordillera de los Andes a la altura de Loja (Cfr. Torero, 1993).

Tampoco pudo ser constatada en las listas la forma <sivisapa>. Creemos acertado asociarla con su similar $<$ llivisupa $>$, patronímico de indios oriundos del pueblo de Azogues. Según la opinión vertida párrafos atrás, /-sapa/ y /-supa/ son alomorfos y estarían a su vez asociados con la final <-shapa>, constatada en topónimos cañarejos y lojanos (Belote y Belote, 1999).

El cuatro patronímico que no tiene coteja en las fuentes es $<$ hinchay $>$. Su perfil fonético sugiere una fricativización de la oclusiva inicial $(/ \mathrm{h} /</ \mathrm{k} /$ ) y una diptongación (/ay/ $</ \mathrm{e} /$ ), procesos ambos que explicarían su origen en la forma barbacoana <kinche $>$. Mientras la fricativización puede explicarse por una regla normal de mudanza fonética, la diptongación podría estar motivada externamente al hallarse en una zona donde es común la final <-ay $>$.

Una última nota merece el patronímico < viñamagua $>$, que aparece una sola vez en las listas, y otra vez bajo la forma apocopada $<$ viñamau $>$. A propósito, es sugerente la existencia de la forma $<$ tene-mawa $>$, porque comprueba que la final $<$-magua $>$ es efectivamente un morfema productivo. Si tomamos en cuenta que la variación $<$-magua $>/<$-mau $>$ sugiere una fonotáctica chicham, distinta de la que encontramos en la onomástica de la sierra centro-sur, cobra sentido la hipótesis de su origen en el pie de monte oriental, donde aparecen los topónimos <yurimaguas $>$ $\mathrm{y}<$ omagua $>$ (cfr. supra).

\section{Balance general de los datos a la luz de los estudios etnohistóricos}

¿Qué conclusiones podemos extraer de los datos presentados con respecto a la composición étnica de la zona de Chuquiribamba? ¿Cómo se relacionan estas conclusiones con la información etnohistórica conocida? Las conclusiones del análisis del corpus patronímico pueden resumirse en tres puntos fundamentales:

- Los patronímicos indígenas de Chuquiribamba presentan al menos seis filiaciones etnolingüísticas distintas: 1) ibérica; 2) quechua; 3) puruhá; 4) cañari; 5) barbacoana (panzaleo); y 6) chicham (palta, malacato). Queda por demostrar una séptima filiación etnolingüística, también chicham, con la lengua rabona del piedemonte oriental.

- Los patronímicos quechuas tienen tres orígenes diferentes: 1) los comunes a la mayoría de variedades del kichwa ecuatoriano; 2) los propios de la variedad imperial cuzqueña; y 3) los característicos de variedades quechuas del centro y sur de los Andes.

- En los últimos 250 años no hubo cambios sustanciales en la composición étnica de la zona, a juzgar por la continuidad, desde 1759 hasta la fecha, de las dos terceras partes de los patronímicos indígenas. 
La presencia de patronímicos quechuas con tres orígenes diferentes se explica, en primer lugar, por la temprana conquista inca de la zona - segunda mitad del siglo XV. Conforme se fue consolidando la presencia político-administrativa inca en el Austro, se formó una base de patronímicos imperiales cuzqueños. Al mismo tiempo, al haber estado poblada la zona por júbaros montañeses de tradición guerrera - paltas y malacatos- la pacificación no se dio sin medidas especiales, una de las cuales fue su deportación a otros lugares del incario, con la venida correspondiente de mitimaes surandinos. A propósito del valle de Loja, Salinas Loyola asegura que los mitimaes eran mucho más numerosos que los indios autóctonos (citado en Casevitz et al., 1988: 207).

Con los mitimaes imperiales vinieron seguramente diferentes variedades quechuas del centro y el sur del Perú - o incluso de Bolivia, si hemos de creer la tradición de que los saraguros son mitimaes del altiplano boliviano. En cualquier caso, la presencia de mitimaes explica por qué se encuentran, entre los patronímicos quechuas, vocablos que no son propios de las variedades del kichwa ecuatoriano. En cuanto a los patronímicos kichwas de origen ecuatoriano, su presencia se explica por una movilidad demográfica colonial relativamente tardía, hacia mediados del siglo XVIII, época en la cual, según estudios recientes, se habría consolidado una variedad del kichwa ecuatoriano diferenciada de los dialectos sureños (Muysken, 2009).

La presencia puruhá y cañari en el corpus toponímico se origina en movimientos demográficos que ocurrieron durante la ocupación inca de los Andes septentrionales, si se toma en cuenta que: 1) el territorio palta había quedado relativamente deshabitado a raíz de la deportación masiva de sus antiguos pobladores; y 2) que puruháes y cañaris fueron pacificados tempranamente y colaboraron a su vez en la pacificación de otras zonas de los Andes septentrionales. Caillavet, por ejemplo, habla de un enclave cañari en Amboca y menciona a Salinas de Loyola (Relación de Loja 1571), según el cual, la provincia estaba poblada por cañaris, paltas y malacatos (Caillavet, 2000: 218, 233). La distribución austral de topónimos y patronímicos puruháes y cañaris se explica asimismo por la cercana afinidad lingüística de ambos grupos, corroborada en características fonéticas que no se encuentran más al norte por ejemplo, la presencia de oclusivas sonoras en posición inicial de palabra y la existencia de una fricativa palatal sonora [ž] - que apuntan "a un origen común o a un largo período de interacción" (Adelaar, 2004: 395, 397).

La presencia de un patronímico de posible origen panzaleo - que seguramente no es el único en la zona austral - seguramente proviene de la presencia de indios forasteros, como los cientos cuyos apellidos se consignan en la lista Cañari-B de Jijón y Caamaño (1943, III: 5-141). Su traslado a la zona pudo haber ocurrido en la época del incario o en las primeras décadas de la conquista. En cualquier caso, de lo que no cabe duda es que el pueblo cañari, cuya zona de influencia se extendió por todo el Austro del Ecuador, actuó como una matriz étnica que conectaba las poblaciones al norte de Chimborazo y aquellas al sur del Azuay, pudiendo incluso haber tenido alguna presencia en el piedemonte andino oriental $\mathrm{y}$, en tal medida, conectar las zonas contiguas de la cuenca amazónica antes y después de la conquista (Casevitz et al., 1988: 206).

La última de las conexiones etnolingüísticas que sugiere el análisis de los topónimos involucra a grupos chicham. Se encontraron tres terminaciones de distribución restringida: la primera, <-ma> / <-namá>, aparece exclusivamente al sur y sureste de la provincia de Loja; las otras dos, <-cus $>/<$-cos $>$ y $<$-magua $>$, ocurren en el piedemonte oriental, en los límites de las provincias serranas de Azuay y Loja con las provincias amazónicas de Morona Santiago y Zamora Chinchipe, e inclusive en el norte del Perú (véase, por ejemplo, Yurimaguas, en la cuenca baja del Santiago). Esta distribución y el hecho de que ambas finales comparten el elemento silábico $<$ ma $>$ - que puede ser shuar o aguaruna según Gnerre y Torero (cfr. supra) - son evidencia clara de su origen chicham, que podría implicar a varios grupos de esta familia etnolingüística. Como sabemos, existía un conjunto jíbaro montañés compuesto por paltas, malacatos y bracamoros (Casevitz et al., 1988: 209). 
Más allá de su afinidad lingüística, los tres grupos se distinguían porque sus territorios se hallaban dispuestos en sentido oeste-este, ocupando los paltas los valles lojanos desde el nacimiento del río Tumbes, los malacatos al este de aquellos, y por fin, los bracamoros al este de estos últimos en el piedemonte oriental (Ibíd.). De acuerdo con esta distribución, la terminación <-ma> y su homóloga <-namá> encajan en la toponimia palta-malacato del sur y sureste de Loja, en tanto que la terminación <-magua $>$ pertenecería a la zona de influencia del tercer grupo chicham montañés, los bracamoros. Es interesante que la misma terminación aparezca en el patronímico híbrido <tenemawa $>$, documentado en la parcialidad de Duma, del pueblo de Sigsig, zona contigua al piedemonte oriental, aunque varios cientos de kilómetros al norte de la cuenca baja del Santiago, donde se suele ubicar a los bracamoros. Por esta razón, es necesario continuar indagando una posible conexión con hablantes de la lengua rabona. Esta, junto con las lenguas bolona y xiroa, eran habladas más al este, en el área de Zamora (Jiménez de la Espada, 1965, III: 42-136). Si recordamos que los bracamoros poblaban precisamente el piedemonte zamorano (Steward y Metraux, 1948, III: 618), no es absurdo sugerir que fueran hablantes de alguna de estas lenguas, con lo cual su presencia en la zona andina, aunque restringida, quedaría confirmada.

\section{Conclusión}

Gracias a su situación geográfica, la región de Loja fue por muchos siglos un cruce de caminos. Por ella se conectaba no sólo el piedemonte amazónico con las hoyas andinas, y estas con el litoral del Pacífico, sino también la costa norte peruana con los Andes septentrionales, y estos con la costa centro-sur del Ecuador. Esta condición, unida a los avatares históricos de su ocupación desde todos estos frentes, explica la riqueza de su onomástica, que no es otra cosa que el testigo de la convivencia histórica de una pluralidad de sociedades y culturas. 


\section{Bibliografía}

Adelaar, Willem y Peter Muysken. 2004, The Languages of the Andes. Cambridge Language Surveys, Cambridge University Press, Cambridge.

Belote, Jim y Linda Belote. 1999, Non-imperial toponymic element distribution in the Ecuadorian Highlands, Manuscrito no publicado.

Caillavet, Chantal. 2000, Etnias del Norte. Etnohistoria e Historia del Ecuador, Abya-Yala, Quito.

Casevitz, Renard et al. 1988, Al Este de los Andes. Relaciones entre las sociedades amazónicas y andinas entre los siglos XV y XVII, Abya-Yala, IFEA, Quito.

Cieza de León, Pedro. 1922 [1553], La Crónica del Perú, Calpe, Madrid.

Costales, Alfredo y Piedad Peñaherrera de Costales. 2002, Etnografia, lingüistica e historia Antigua de los Caras o Yumbos Colorados (1534-1978), Abya-Yala y IEAG, Quito.

Gnerre, Maurizio. 1975, "L'utilizzazione delle fonti documentarie dei secoli XVI e XVII perla storia linguistica Jíbaro", en: Cerulli E.y G. Della Ragione (Ed.), Atti del XL Congresso Internazionale degli Americanisti vol. 3, editado por. Genoa, Tilgher, pp. 79-86.

Gómez Rendón y Jorge Arsenio. 2015, Los “Colorados": etnohistoria y toponimia, Universidad Andina Simón Bolívar, Sede Ecuador, Quito.

González Suárez, Federico. 1967, Notas arqueológicas y Prehistoria ecuatoriana, Editorial J.M. Cajica, Jr., Puebla.

Hocquenghem, Anne-Maríe et al. 1993, "Bases del intercambio entre las sociedades norperuanas y surecuatorianas: una zona de transición entre 1.500 A.C. Y 600 D.C", en: Bulletin de l'Institut Français d'Études Andines, 22 (2), pp. 243-256.

Jijón y Caamaño, Jacinto. 1919, "Contribución al conocimiento de las lenguas indígenas que se hablaron en el Ecuador Interandino y Occidental, con anterioridad a la Conquista Española. Ensayo Provisional", en: Boletín de la Sociedad Ecuatoriana de Estudios Históricos Americanos, No. 6, edición especial, Quito.

1998, El Ecuador interandino y occidental antes de la conquista castellana, Editorial Ecuatoriana, vol. 1 (1940), vol. 2 (1941), vol. 3 (1943), vol. 4 (1945), Abya Yala, edición facsimilar, Quito.

Jiménez de la Espada, Marcos. Relaciones Geográficas de Indias: Perú. 3 Vols. Biblioteca de Autores Españoles 183-5, Madrid: Atlas, 1965 [1586].

Muysken, Pieter. 2009, "Gradual restructuring in Ecuadorian Quechua”, en: Selbach, R. et al. (Eds.) Gradual Creolization: Studies Celebrating Jacques Arends, Benjamins, Ámsterdam, pp. 77-100.

Paz y Miño, Luis Telmo. "Las lenguas indígenas del Ecuador. Diccionario Toponímico". Boletín de la Academia Nacional de Historia, Vol. XLIII-LVIX, №. 98, 1961-1964

"Las agrupaciones y lenguas indígenas del Ecuador en 1500 y 1959", en: Boletín de la Academia Nacional de Historia, Vol. 43, No. 97, 1961

"Lenguas Indígenas del Ecuador: I Pasto, II Kara, III Panzaleo, y IV Puruguay", Boletín de la Academia Nacional de Historia, Nos. 56, 57 y 59, 1940-42, Quito-Ecuador.

Pérez, Aquiles. 1962, "Los Seudo-pantsaleos", Llacta No. 14. Quito.

Steward, Julian H. y Alfred Metraux. 1948, "Tribes of the Peruvian and Ecuadorian Montaña”, en: Steward J. y A. Metraux (Eds.), The Handbook of South American Indians, Washington, United States Government Printing Office, The Tropical Forest Tribes, Vol. III, United States, pp. 535-656.

Torero, Alfredo. 1993, "Lenguas del nororiente peruano: la hoya de Jaén en el siglo XVII, en: Revista Andina 22, Cuzco, pp. 447-472.

Torres Fernández de Córdova, Glauco. 2002, Lexicón Etnolectológico del Quichua Andino, Tumipanpa, 3 vols., Cuenca. 
